\title{
STUDIES ON THE INFLUENCE OF THE LOW SODIUM CARDIAC DIET AND THE KEMPNER REGIMEN ON RENAL HEMO- DYNAMICS AND ELECTROLYTE EXCRETION IN HYPERTENSIVE SUBJECTS ${ }^{1,2,3}$
}

\author{
By R. E. WESTON, L. HELLMAN, D. J. W. ESCHER, ${ }^{4}$ I. S. EDELMAN, ${ }^{5}$ \\ J. GROSSMAN, AND L. LEITER \\ (From the Medical Division, Montefiore Hospital, Nez' York)
}

(Submitted for publication October 31, 1949; accepted, January 30, 1950)

Until recently, renal function in man has been considered to be relatively unaffected by variations in dietary salt and protein $(1,2)$, which produce marked renal hemodynamic changes in the dog $(3,4)$. However, studies on normal subjects and patients in congestive failure suggest that changes in glomerular filtration rate may influence urinary sodium output as sodium intake is varied (5). The present report is concerned with the effects of dietary salt and protein restriction on renal function and electrolyte excretion in a series of hypertensive subjects, who were studied on a regular hospital diet, a low salt cardiac diet, and the Kempner rice diet (6), in which both salt and protein are markedly reduced.

\section{CLINICAL MATERIAL AND METHODS}

The nine hypertensive patients in this series all had long established hypertension without any clinical or laboratory evidence of either cardiac failure or renal pathology other than that associated with essential hypertension. Because of a previous episode of congestive failure, one patient (J. B.) was maintained on digitalis and remained well compensated throughout the course of these investigations. Another (R. G.) had a previous cerebral accident with no residual neurological signs. A third (M. C.) had a coexisting chronic lymphatic leukemia. On the basis of the usual criteria (7), one patient

1 Presented to American Physiological Society, Atlantic City, N.J., March 18, 1948.

2 Supported in part by grants from the National Heart Institute, U. S. Public Health Service, and the Martha M. Hall Foundation.

3 The Normal Serum Albumin used in these studies was prepared by the American National Red Cross from the blood of voluntary donors. This material has been supplied to investigators by the American Red Cross as part of its National Blood Program. The opinion and conclusions are those of the authors and do not necessarily reflect the policy of the National Blood Program.

4 Rosenstock Memorial Foundation Fellow in Medicine.

5 Dazian Foundation Fellow in Medicine.
(I. G.) could be considered to be in the malignant phase of hypertension.

Each patient was followed for three or more weeks on the regular hospital diet, containing $65 \mathrm{gms}$. of protein and approximately 3-4 gms. (130-175 m.eq.) of sodium, and on the Kempner rice diet, containing approximately 20 gms. of protein and less than 0.2 gm. (3-9 m.eq.) of sodium. Six of the patients also were studied on a cardiac low salt diet, containing $65 \mathrm{gms}$. of protein and $0.5-0.8$ gm. (20-35 m.eq.) of sodium. Several were maintained on either the low salt or the rice diet for periods much longer than three weeks (Table I). One patient (C. M.) was followed, in addition, for a five day period in which sodium chloride was added to the rice diet. To diminish the possibility of chance errors resulting from experimental design, the sequence in which individual patients were placed on low and high salt diets was varied. To promote the loss of sodium, mercurial diuretics were administered to several patients (J. B., C. DeC., A. M.) on the rice diet, until they became relatively unresponsive (8).

Recumbent blood pressures were taken by the same observer daily on each patient shortly after awakening in the morning and after 30 minutes bed rest in mid-afternoon. Most patients were weighed each morning on the the same scale. Daily urinary chloride outputs were measured to check the patients' salt intake.

At appropriate intervals on the various regimens, renal clearances of mannitol, para-aminohippurate, urea, sodium, chloride and creatinine, and maximal tubular capacity for excreting para-aminohippurate $\left(\mathrm{T}_{\mathrm{mPAH}}\right)$ were determined on resting patients, at least 14 hours after the previous evening meal, by the constant-infusion clearance technique (9). Blood samples generally were drawn from an indwelling femoral arterial needle, inserted after local infiltration with Metycaine. During each clearance determination, blood pressure was taken with a mercury sphygmomanometer. To insure adequate tubular PAH loads, during $\mathrm{Tm}$ determinations in these hypertensive patients with decreased renal plasma flows very high PAH plasma levels, ranging from 0.8 to 1.3 mgm. per cc., were maintained.

Except in the special circumstances below, plasma volumes were determined by the direct method with $\mathrm{T}$ 1824 (10), before starting the infusion of PAH and man. nitol. Plasma dye concentration at time of injection was 


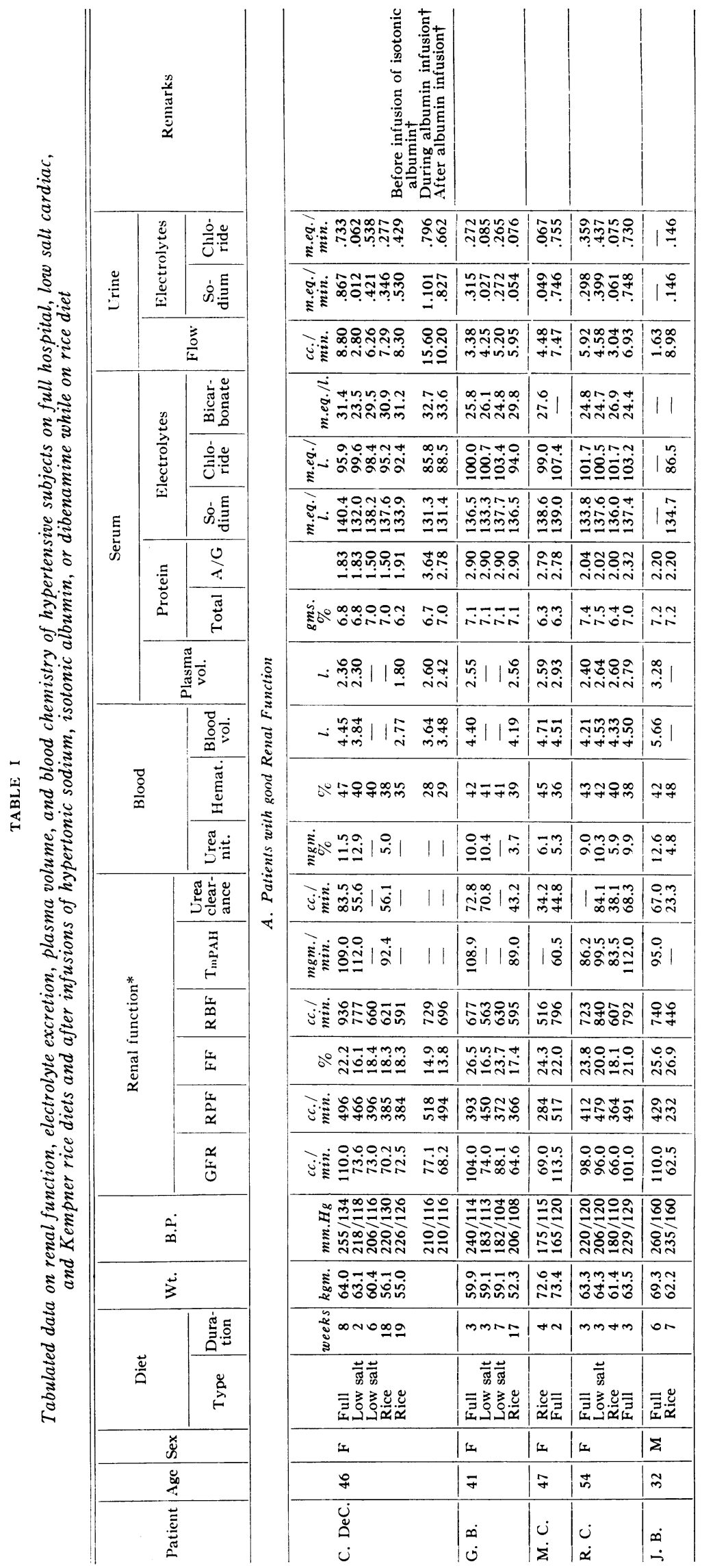




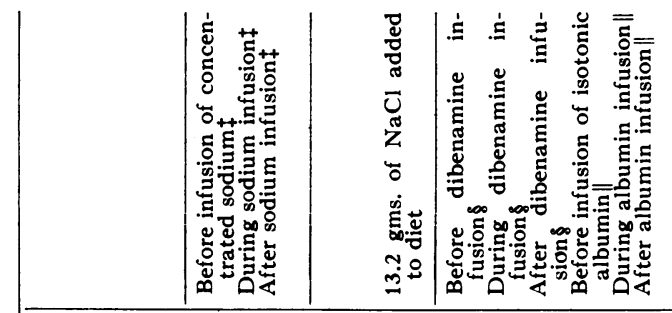

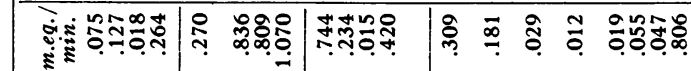

\begin{tabular}{|c|}
\hline 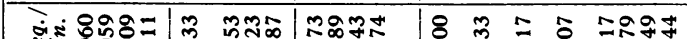 \\
\hline
\end{tabular}

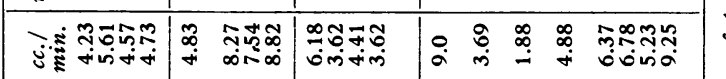

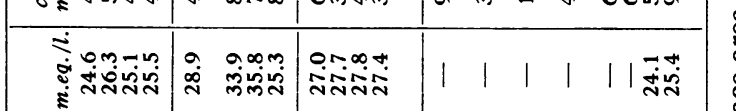

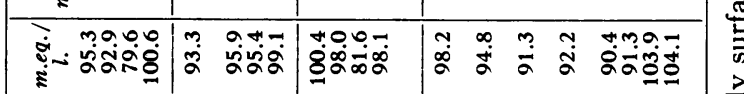

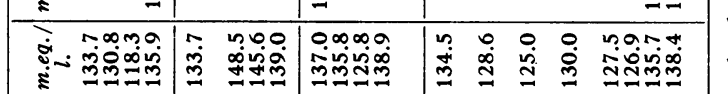

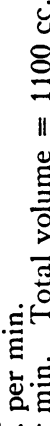

$\sum_{i}$

I

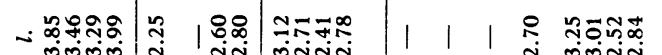

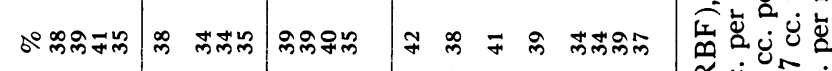

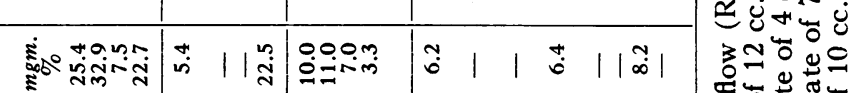

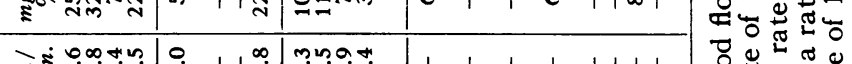

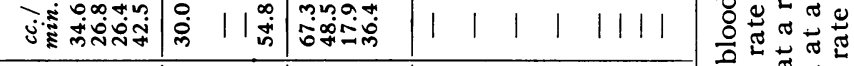

$\infty$

|

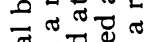

एँ

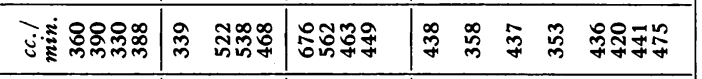

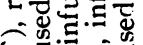

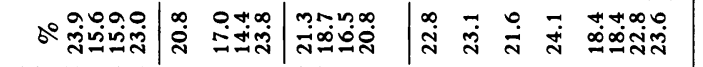

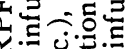

\begin{tabular}{|c|c|c|c|}
\hline & 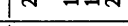 & $\mathrm{d}$ & \\
\hline 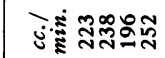 & 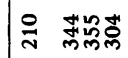 & 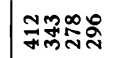 & |艹⿱乛龰 \\
\hline
\end{tabular}

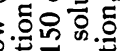

s

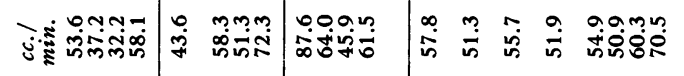

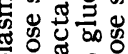

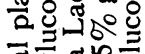

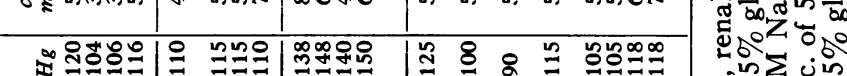

4⿻一𠃋十

in $\Sigma$ in

ชิ.50.5

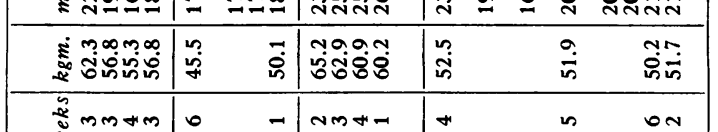

U.

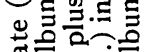

ㅎำ ह

둘

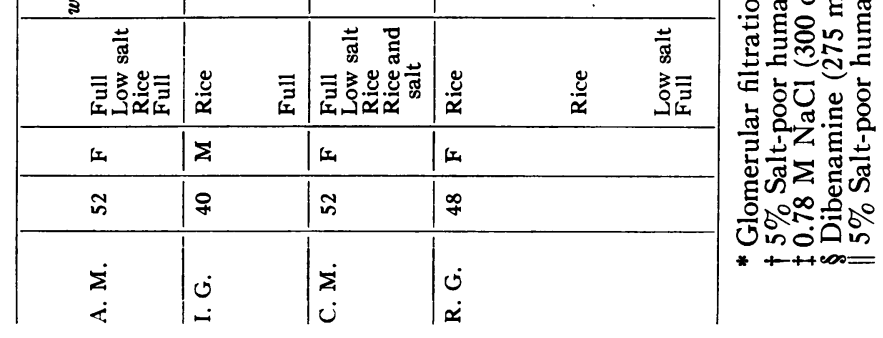


obtained by extrapolation of dye concentration, plotted semi-logarithmically against time of collection.

Analyses for mannitol and PAH in blood and urine, appropriately diluted to give $\mathrm{U} / \mathrm{P}$ ratios approximating unity in the samples analyzed, were by the usual methods (9). PAH was acetylated before determination of mannitol, as suggested by Barker and Clark (11). The other determinations on serum and urine were performed as follows: Sodium by the gravimetric method of Butler and Tuthill (12); chloride by either a modified Volhard method (13) or by Van Slyke's modification of Sendroy's iodometric method (14); urea gasometrically in the Van Slyke manometric apparatus (15): creatinine by either the Folin-Wu (16) or a modification of Phillip's method (17) ; serum proteins and $A / G$ ratios by the method of Campbell and Hanna (18): serum concentration of the blue dye, T-1824, by means of the Beckmann spectrophotometer or a Fisher photo-electric colorimeter; hematocrits in Wintrobe tubes spun for 30 minutes at 3,000 rpm.

\section{RESULTS}

Table I contains all data on each patient, including the sequence of dietary changes. The renal hemodynamic and the urinary electrolyte and volume data are averages of at least three clearance periods, preceding the $T_{\mathrm{mPAH}}$ determinations. Blood pressure, serum electrolyte concentrations, hematocrits, etc., when not constant throughout, are mid-point values during these periods. In the tables the nine subjects are separated into two groups on the basis of renal function. All mannitol and PAH clearances, and $T \mathrm{~m}_{\mathrm{PAH}}$ values are corrected for body surface area.

Glomerular filtration rates ${ }^{6}$ in these hypertensives ranged from 114 to $53 \mathrm{cc}$. per min. per 1.73 $\mathrm{M}^{2}$ on control diets. While on the low salt cardiac diet, five of the six patients had a $15-33 \%$ decrease in mannitol clearance. Despite the small number in this series, this reduction in glomerular filtration rate approaches being statistically (20) significant (D.F. $=5$, “t” $=3.80, \mathrm{P}=0.012$ ). In all nine patients the additional salt and/or protein restriction of the Kempner regimen, plus repeated mercurial injections in three of the nine, led to a decrease in glomerular filtration rate to values $28-47 \%$ below the control values, a difference which is statistically highly significant (D.F. = 8 , “t” $=8.98, \mathrm{P}=0.0001)$. In the two patients (R. C. and A. M.) who were again placed on the

\footnotetext{
6 Mannitol clearance was used as an index of filtration rate although it is recognized that some tubular reabsorption of this hexose does occur (19).
}

full diet, the glomerular filtration rate returned to previous control values (cf. Table I).

The importance of salt restriction alone may be illustrated by patient C. DeC., in whom 17 days on the cardiac low salt diet produced a marked decrease in glomerular fltration rate which remained unchanged after an additional nine weeks on this regimen. Subsequently, four months on the rice diet, with bi-weekly administration of mercurial diuretics for the last four weeks, resulted in weight loss of $4.3 \mathrm{kgm}$. with no appreciable further decrease in glomerular filtration rate or renal plasma flow.

Generally, variations in the mannitol clearances were associated with parallel changes in urea and creatinine clearances. Figure 1 shows the absence of any significant deviation in mannitol/urea clearance ratio on either the low salt or the rice diet. In spite of the reduced urea clearance with the decreased protein intake on the rice diet, the BUN fell significantly in every case.

Effective renal plasma flor's, as measured by clearance of PAH, ranged from 517 to $223 \mathrm{cc}$. per min. per $1.73 \mathrm{M}^{2}$ on control diets, almost all below the average normal figures (9). The reduction in renal plasma flow with restriction of salt and protein intake was not as constant or as marked as that in filtration rate. Moreover, this decrease was less apparent in the possibly more apprehensive patients (G. B., R. C., A. M.), in whom the renal plasma flow on the full diet may have been

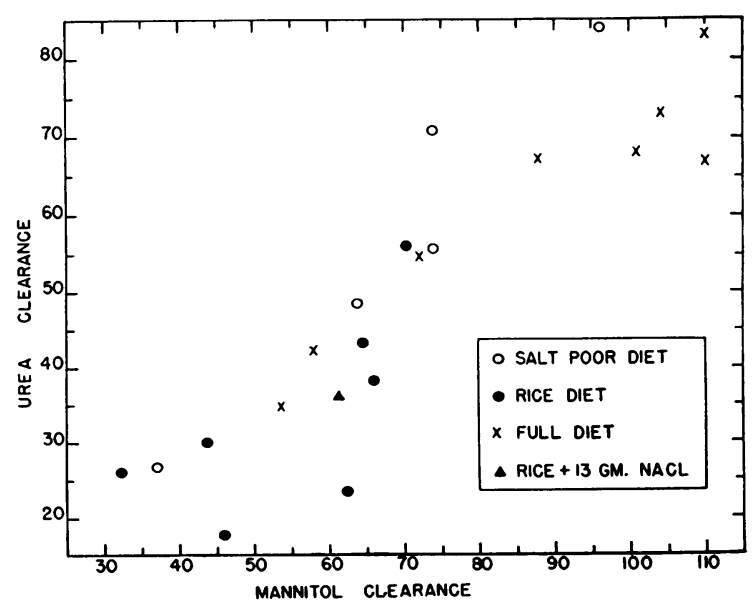

Fig. 1. Relationship Between the Urea and Mannitol Clearances in Hypertensive Patients on Full, Low salt Cardiac, and Rice Diets 


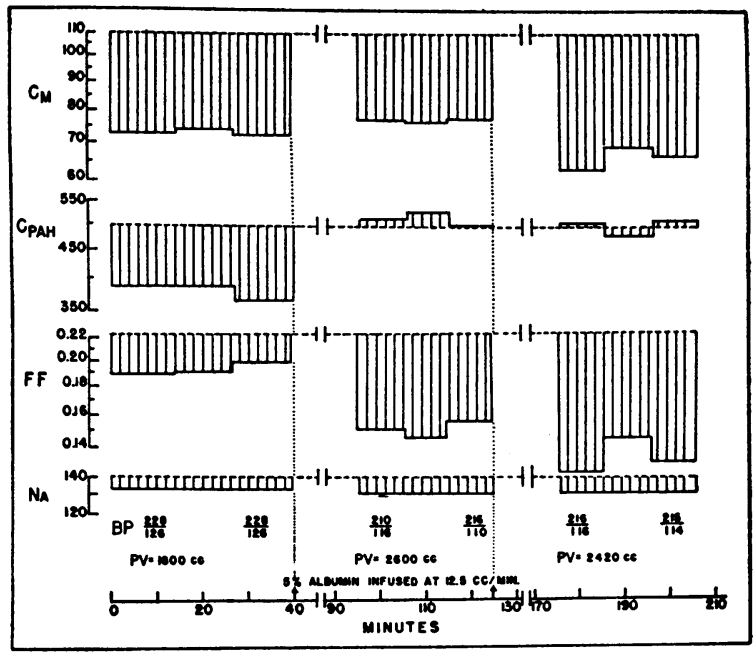

Fig. 2. The Effects on Renal Hemodynamics, Serum Sodium Concentration, Plasma Volume, and Blood Pressure Produced by Rapidly Infusing $1100 \mathrm{cc}$. of an Isotonic (5\%) Salt-poor Human Albumin Solution in a Hypertensive Patient (C. DeC.) on the Rice Diet

abnormally low because of the anxiety associated with the first clearance study, as reported by Barclay (21). When compared with renal plasma flow in the full diet, the decrease in renal plasma flow on the low sodium cardiac diet was not statistically significant (D.F. $=5$, “ $\mathrm{t}$ " $=3.04, \mathrm{P}=$ 0.028 ), whereas the decrease on the rice diet was statistically highly significant (D.F. $=8$, " $\mathrm{t}$ " $=$ 5.08, $\mathrm{P}=0.001$ ).

The filtration fraction (F.F.), the ratio of $\mathrm{C}_{\mathrm{M}} /$ $\mathrm{C}_{\mathbf{P A B}}$, in these hypertensive subjects on full diets ranged from 0.21 to 0.27 . It tended to fall on low salt and rice diets, since there was a smaller decrease in renal plasma flow than in glomerular filtration rate, and returned to control levels when patients were restored to full diets (Table I).

The maximal tubular capacity for excreting para-aminohippurate $\left(T_{m P A H}\right)$ decreased in three of five patients on the rice diet. However, in the presence of high plasma levels of $\mathrm{PAH}$, small errors in filtration rate may produce greater variation in $T_{\text {mPAH}}$, thereby contributing to the lack of statistically significant changes observed in the latter function in this small series. The levels of $T_{\text {mPAB }}$ and filtration rate on the full diet permitted differentiation of the patients into two groups on the basis of renal function (Table I).

Plasma volume also tended to decrease with salt restriction as others have reported (22), but the changes in this small series are not statistically significant. When compared with plasma volume on the full diet, plasma volume on the rice diet decreased $10-25 \%$ in five patients with good ( $\mathrm{M}$. C. and C. DeC.) or impaired (C. M., I. G. and A. M.) renal function and did not change significantly in three others with good (R. C., G. B.) or poor (R. G.) function.

The influence of plasma volume alterations on the renal hemodynamic changes resulting from salt and protein restriction. Since salt restriction reduces extracellular fluid volume and plasma volume which in turn may influence renal function, the renal hemodynamic effects produced by rapidly increasing the plasma volume with salt-poor human albumin infusions were studied in two hypertensive patients on the rice diet, one (C. DeC.) with good and the other (R. G.) with reduced renal function. Approximately, $1100 \mathrm{cc}$. of a $5 \%$ solution of human albumin, made isotonic with plasma by adding glucose and mannitol, were infused at a rate of $10-12 \mathrm{cc}$. per min.

The responses in both patients were qualitatively the same (cf. Table I) and are illustrated in Figure 2 from the data on patient C. DeC. At the start

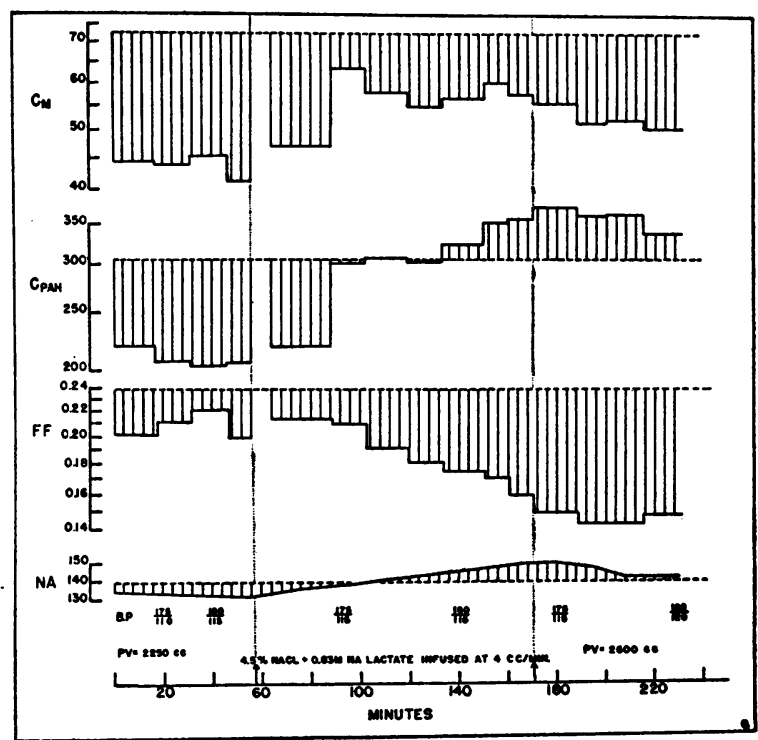

Fig. 3. The Effects on Renal Hemodynamics, Serum Sodium Concentration, Plasma Volume, and Blood Pressure Produced by Infusion of $300 \mathrm{cc}$. of $0.78 \mathrm{M}(4.5 \%) \mathrm{NaCl}$ plus $150 \mathrm{cc}$. OF $0.83 \mathrm{M}$ NaLaCtate at a Rate of 4 cC. PER Min. in Hypertensive Patient I. G. on the Rice Diet 
TABLE II

Effect of rice diet and concentrated sodium infusion during rice diet on renal hemodynamics and serum and urine electrolytes in a non-hypertensive subject

\begin{tabular}{|c|c|c|c|c|c|c|c|c|c|c|c|c|c|c|c|c|}
\hline \multicolumn{2}{|l|}{ Diet } & \multirow{3}{*}{ Wt. } & \multirow{3}{*}{ B.P. } & \multirow{3}{*}{ Hemat. } & \multirow{2}{*}{\multicolumn{5}{|c|}{ Renal function* }} & \multicolumn{4}{|c|}{ Serum } & \multicolumn{3}{|c|}{ Urine } \\
\hline \multirow[b]{2}{*}{ Type } & \multirow[b]{2}{*}{$\left|\begin{array}{c}\text { Dura- } \\
\text { tion }\end{array}\right|$} & & & & & & & & & \multicolumn{2}{|c|}{ Protein } & \multicolumn{2}{|c|}{ Electrolytes } & \multirow{2}{*}{ Flow } & \multicolumn{2}{|c|}{ Electrolytes } \\
\hline & & & & & GFR & RPF & FF & RBF & $\mathrm{T}_{\mathrm{mPAH}}$ & Total & $A / G$ & Sodium & Chloride & & Sodium & Chloride \\
\hline Rice & $\begin{array}{c}\text { weeks } \\
2\end{array}$ & $\begin{array}{c}\mathrm{kgm} . \\
53\end{array}$ & $\begin{array}{l}m m . H g \\
112 / 74\end{array}$ & $\begin{array}{c}\% \\
42.7\end{array}$ & $\begin{array}{c}c c_{i} / \\
\min . \\
87\end{array}$ & $\begin{array}{l}c c_{.} / \\
\min . \\
491\end{array}$ & $\begin{array}{c}\% \\
17.7\end{array}$ & $\begin{array}{l}c c_{.} \\
\min . \\
857\end{array}$ & 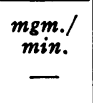 & $\begin{array}{c}\mathrm{gms} . \\
5.84\end{array}$ & 1.71 & m.eq./l. & \begin{tabular}{|c|} 
m.eq./l. \\
102.4
\end{tabular} & $\begin{array}{c}c c . / \\
\text { min. } \\
13.0\end{array}$ & $\begin{array}{c}\text { m.eq./ } \\
\text { min. } \\
-\end{array}$ & $\begin{array}{c}\text { m.eq./ } \\
\text { min. } \\
0.0155\end{array}$ \\
\hline Rice & 4 & 50 & $110 / 72$ & 37.2 & 92 & 455 & 20.2 & 736 & 一 & 5.74 & 2.50 & 132.8 & 97.4 & 7.3 & 0.0049 & 0.0029 \\
\hline $\begin{array}{l}\text { After sodium } \\
\text { infusion } \dagger\end{array}$ & - & 一 & 一 & 32.0 & 106 & 611 & 17.3 & 896 & - & 4.77 & 2.04 & 138.4 & 101.5 & 2.32 & 0.1422 & 0.0991 \\
\hline Full diet & 10 & 57.2 & $110 / 72$ & 41.7 & 116 & 543 & 21.8 & 931 & 110 & 5.74 & 3.10 & 136.3 & 104.4 & 11.6 & 0.284 & 0.333 \\
\hline
\end{tabular}

* Glomerular filtration rate (GFR), renal plasma flow (RPF), renal blood flow (RBF) and $T_{\text {mPAB }}$ corrected to a surface area of $1.73 \mathrm{M}^{2}$.

$\uparrow$ See text.

of this procedure, after 19 weeks on the rice diet, C. DeC.'s plasma volume, glomerular filtration rate, and renal plasma flow were $78 \%, 66 \%$, and $77 \%$, respectively, of values on the full diet. With the infusion of the $5 \%$ albumin solution, plasma volume and renal plasma flow ${ }^{7}$ quickly increased to the previous full diet levels, whereas glomerular filtration rate at first remained unchanged and later decreased slightly.

The effect of concentrated sodium infusion on renal hemodynamics in patients on the rice diet. In view of the preceding results with salt-free albumin, the effect of administering concentrated sodium solutions was studied. Figure 3 presents the changes in serum electrolytes, plasma volume, and renal hemodynamics before, during and after the slow intravenous infusion of a solution, containing $300 \mathrm{cc}$. of 0.78 Molar sodium chloride and 150 cc. of 0.83 Molar sodium lactate, in patient I. G., who had been on the rice diet for approximately six weeks (Table I).

During the concentrated sodium infusion, there

7 Since Cargill (23) has reported that administration of concentrated human albumin in man results in decreased renal para-aminohippurate extraction, it was recognized that the renal plasma flow changes after albumin administration may have been even greater than those recorded. However, by renal vein catheterization we found no change in PAH extraction after administration of isotonic albumin solution as described above to one subject in congestive failure, who had been on the rice diet for 12 weeks (24). was not only rapid increase in serum sodium concentration and renal plasma flow to values greater than on the full diet, but also a smaller but significant increase in filtration rate. After the completion of this infusion, renal plasma flow continued to increase, whereas serum sodium concentration and filtration rate decreased somewhat. No significant changes in blood pressure or temperature occurred. However, after the infusion was completed, there was significant hemodilution, as reflected by a $10 \%$ decrease in hematocrit and serum protein concentration, which may have contributed to the increase in filtration rate.

This procedure was repeated on one non-hypertensive subject (J. P.), a 23 year old female with suspected congenital heart disease but no evidence of failure, who had been on the rice diet for four weeks, and similar results were obtained (Table II).

Influence of sympathetic nervous system on renal response to salt restriction. To test the possible role of neurogenic factors in maintaining the decrease in filtration rate and renal plasma flow with salt restriction, dibenamine ${ }^{8}(\mathrm{~N}, \mathrm{~N}$, dibenzyl $\beta$ chloro ethylamine), an adrenergic blocking drug, was administered to patient $R$. G., who had been on the rice diet for three weeks. During three control clearance periods, blood pressure averaged 230/125. After $275 \mathrm{mgm}$. of dibenamine

${ }^{8}$ Dr. Henry Haimovici supplied the dibenamine and assisted in conducting the experiment. 
were injected in $450 \mathrm{cc}$. of $5 \%$ glucose solution at the rate of $7 \mathrm{cc}$. per min., glomerular filtration rate, renal plasma flow, blood pressure, and serum electrolytes all were somewhat reduced. Three and one-half hours later, as the dibenamine took full effect and the blood pressure dropped to $160 / 90$, glomerular filtration rate and renal plasma flow returned to, but did not exceed, pre-dibenamine levels on the rice diet (Table I). However, the serum sodium concentration was 10 m.eq. per 1 . lower than at the start of the experiment, probably due to the sodium diuresis from the rapid administration of the $5 \%$ glucose solution to a depleted patient.

Renal resistances were calculated by means of Lamport's improved formulae (25) and corrected for changes in blood viscosity. On the full diet these patients all had increased renal afferent $(\mathrm{Ra})$, efferent $(\mathrm{Re})$ and total $(\mathrm{Rr})$ arteriolar resistances with an increased $\mathrm{Ra} / \mathrm{Re}$ ratio. On the low salt cardiac diet, there were no consistent significant changes. On the rice diet there was no consistent change in $\mathrm{Re}$ but in seven of nine patients there was an increase in $\mathrm{Ra}$ and, therefore, in Rr. After infusions of isotonic albumin, dibenamine, or concentrated sodium solutions, there was a decrease in $\mathrm{Ra}, \mathrm{Re}$, and $\mathrm{Rr}$, with a variable change in the $\mathrm{Ra} / \mathrm{Re}$ ratio.

Salt excretion decreased in both groups of patients when the salt content of the diet was reduced, but the sodium and chloride excretion during renal clearance periods were not as low as would be expected. In contrast, the 24 -hour chloride excretions balanced well against the known

TABLE III

Relationship between urine volume and electrolyte excretion in normal and hypertensive subjects with good renal function

\begin{tabular}{|c|c|c|c|c|c|c|c|}
\hline Patient & B.P. & Diet & $\mathrm{T}_{\mathrm{mPAB}}{ }^{*}$ & GFR* & Urine flow & $\begin{array}{c}\text { Sodium } \\
\text { excretion }\end{array}$ & $\begin{array}{l}\text { Chloride } \\
\text { excretion }\end{array}$ \\
\hline A. D. & $\begin{array}{r}m m . H_{g} \\
120 / 85\end{array}$ & Full & ${ }^{m g m . / m i n}$ & $\begin{array}{c}c c . / \min . \\
150.0 \\
151.0 \\
158.0\end{array}$ & $\begin{array}{c}c c . / \min . \\
6.54 \\
6.52 \\
8.49\end{array}$ & $\begin{array}{c}\text { m.eq./min. } \\
0.342 \\
0.319 \\
0.336\end{array}$ & $\begin{array}{c}\text { m.eq./min. } \\
0.448 \\
0.458 \\
0.508\end{array}$ \\
\hline N. G. & $110 / 70$ & Low salt & - & $\begin{array}{l}59.0 \\
62.0 \\
52.0 \\
61.0\end{array}$ & $\begin{array}{l}3.45 \\
6.66 \\
2.15 \\
1.61\end{array}$ & $\begin{array}{l}0.047 \\
0.072 \\
0.070 \\
0.053\end{array}$ & $\begin{array}{l}0.088 \\
0.071 \\
0.071 \\
0.071\end{array}$ \\
\hline D. M. & $110 / 80$ & Full & - & $\begin{array}{l}97.5 \\
96.7 \\
91.9\end{array}$ & $\begin{array}{l}2.37 \\
3.11 \\
5.96\end{array}$ & $\begin{array}{l}0.162 \\
0.161 \\
0.172\end{array}$ & $\begin{array}{l}0.229 \\
0.232 \\
0.255\end{array}$ \\
\hline R. W. & $128 / 78$ & $\begin{array}{l}\text { Full plus } \\
\mathrm{NH}_{4} \mathrm{Cl}\end{array}$ & - & $\begin{array}{l}97.6 \\
96.5 \\
96.6\end{array}$ & $\begin{array}{c}13.8 \\
11.0 \\
5.78\end{array}$ & $\begin{array}{l}0.276 \\
0.273 \\
0.274\end{array}$ & $\begin{array}{l}0.349 \\
0.326 \\
0.315\end{array}$ \\
\hline R. C. & $229 / 129$ & Full & 112 & $\begin{array}{l}94.0 \\
96.0 \\
92.0\end{array}$ & $\begin{array}{l}8.26 \\
6.66 \\
5.86\end{array}$ & $\begin{array}{l}0.972 \\
0.692 \\
0.597\end{array}$ & $\begin{array}{l}0.922 \\
0.698 \\
0.570\end{array}$ \\
\hline \multirow{2}{*}{ C. DeC. } & $255 / 134$ & Full & 108 & $\begin{array}{r}114.0 \\
107.0 \\
97.0\end{array}$ & $\begin{array}{r}11.30 \\
8.66 \\
6.48\end{array}$ & $\begin{array}{l}1.14 \\
0.870 \\
0.630\end{array}$ & $\begin{array}{l}0.972 \\
0.716 \\
0.518\end{array}$ \\
\hline & $226 / 126$ & Rice & - & $\begin{array}{l}72.2 \\
72.8 \\
73.8\end{array}$ & $\begin{array}{c}10.5 \\
8.36 \\
7.20\end{array}$ & $\begin{array}{l}0.625 \\
0.532 \\
0.474\end{array}$ & $\begin{array}{l}0.418 \\
0.379 \\
0.368\end{array}$ \\
\hline J. B. & $235 / 160$ & Rice & 110 & $\begin{array}{l}63.0 \\
56.0 \\
61.0\end{array}$ & $\begin{array}{c}10.5 \\
9.58 \\
6.90\end{array}$ & $\begin{array}{l}0.204 \\
0.141 \\
0.102\end{array}$ & $\begin{array}{l}0.204 \\
0.151 \\
0.095\end{array}$ \\
\hline G. B. & $240 / 114$ & Full & 108 & $\begin{array}{r}117.5 \\
95.3 \\
103.0\end{array}$ & $\begin{array}{l}4.85 \\
2.89 \\
2.41\end{array}$ & $\begin{array}{l}0.512 \\
0.266 \\
0.206\end{array}$ & $\begin{array}{l}0.438 \\
0.236 \\
0.174\end{array}$ \\
\hline
\end{tabular}

* Corrected to body surface area of $1.73 \mathrm{M}^{2}$. 
intakes. For example, in 24 hours patient J. B. on the rice diet excreted less than 9 m.eq. of chloride. On the other hand, during renal clearance studies, his chloride and sodium output in urine was 0.146 m.eq. per min., equivalent to $200 \mathrm{~m} . e q$. per day. However, his average urine flow during the 24-hour period was 0.85 cc. per min., whereas, during the clearance periods, it was 8.98 cc. per min., as a result of the water and mannitol diuresis.

At the plasma levels employed in these cases, the osmotic effect of the mannitol in the tubular urine may increase sodium and chloride excretion, but in normal subjects this increased electrolyte excretion generally is not proportional to urine volume. In Table III are presented data on the relationship between urine volume and electrolyte excretion in four non-hypertensive subjects and four representative hypertensives with normal $\mathrm{T}_{\mathrm{mPAB}}$ values, who had varying urine volumes during successive mannitol and $\mathrm{PAH}$ clearance periods, prior to $T_{\mathrm{mPAH}}$ determinations. It is apparent that unlike normal subjects, these hypertensives exhibit a proportionality between urine volume and sodium and chloride excretion on both high and low sodium intake. In patients R. C. and and C. DeC., for example, salt excretion bears an almost direct relationship to urine volume.

Serum electrolyte changes. In patients with fairly normal glomerular filtration rates and $T_{\text {mPAH's, }}$, the change in serum sodium and chloride concentration after even months on the rice diet was slight, whereas in the patients with low glomerular filtration rate and reduced $\mathrm{T}_{\mathrm{mPAB}}$ on full diets, there was a marked and rapid drop in these serum electrolytes with severe sodium restriction; serum bicarbonate did not change appreciably.

Significant decrease in both diastolic and systolic blood pressure with the rice diet was observed in only one (R. C.) of this small series of patients, most of whom were on the diet for relatively short periods. After 12 days on the Kempner diet, her morning resting pressures dropped to $150 / 90$ and, on one occasion, to $140 / 80$, but she exhibited the usual diurnal vascular lability. On the morning of her renal clearance tests on the rice diet, her pressure was 180/110. Fifteen days after resumption of the full diet, her morning resting pressure had returned to $160 / 100$. In another pa- tient (A. M.), systolic pressure decreased markedly during the rice diet period.

\section{DISCUSSION}

Although it is well recognized that renal blood flow and glomerular filtration rate in the dog may vary markedly with change in protein or salt intake $(3,4)$, the corresponding renal functions in man have been considered relatively resistant to such dietary influences (1). However, there have been repeated demonstrations (26-28) that in normal men or convalescent nephritics, urea clearance decreases $20-30 \%$ when protein intake is reduced, but does not change significantly when the protein intake is increased to as much as 280 gms. per day. This protein intake, as Goldring and his colleagues (27) have noted, is small in comparison with the 15 gms. per $\mathrm{kgm}$. which produces a supernormal renal blood flow in the $\operatorname{dog}(3)$.

Similarly, evidence has been accumulating that acute changes in body sodium chloride may have marked renal hemodynamic effects in man. McCance and Widdowson (29) reported a 25-30\% decrease in the clearances of endogenous creatinine, urea, sucrose, or inulin in five normal men, in whom acute salt deficiency was produced by the low salt diet plus severe sweating induced by artificial heat. Conversely, others have observed significant increases in filtration rate during rapid infusion of concentrated sodium solutions in normal men (30), and patients with diabetes insipidus (30) or congestive failure $(8,31)$, as well as in normal dogs and dogs with diabetes insipidus (32).

However, prior to the present study, the only published report of the effects on renal hemodynamics of moderately and severely reduced salt intake, uncomplicated by rapidly dehydrating procedures, was Cope's statement (26) that urea clearance is unchanged on a low salt diet in normal subjects and nephritics with daily urinary sodium chloride excretions of less than $1 \mathrm{gm}$. Our results demonstrate that glomerular filtration rate and renal plasma flow may change significantly as salt intake is decreased in hypertensive subjects with good or poor renal function.

Since the completion of this work, several investigators have confirmed these findings. Chasis 
and his associates (33) have reported similar hemodynamic changes in hypertensive subjects on the Kempner regimen and concluded that the decreases in glomerular filtration rate and renal plasma flow and $T_{\mathrm{mPAH}}$ were significant. Currens and his colleagues (34), Sirota (35), and Cargill (36) have made similar observations on smaller numbers of hypertensives. Bradley (37) also has observed a decrease in the glomerular filtration rate and renal plasma flow in several hypertensive patients placed on a low salt diet for six to nine days.

The nature of the mechanism relating salt or protein intake to renal hemodynamic functions remains obscure. Rhoads and his associates (38) demonstrated that the variations in renal blood flow with protein intake in the dog were unaffected by denervation of the kidney. Our results in the single dibenamine experiment tentatively suggest that the decreased renal plasma flow and glomerular filtration rate observed in hypertensives on the rice diet may be similarly unaffected by this pharmacological sympathectomy. Furthermore, recent evidence indicates that there may be other marked chronic changes in renal hemodynamics, which are relatively independent of neural influences (39-42).

In addition, the characteristic renal hemodynamic change observed with salt and protein restriction-a relatively greater decrease in glomerular filtration rate than in renal plasma flow, resulting in a decreased filtration fraction-is not typical of the renal response to known humoral substances with potential renal hemodynamic actions, such as angiotonin (43), VEM (44), or epinephrine (45). However, when the plasma volume was rapidly increased in two of our patients on low sodium regimens by the infusion of isotonic albumin solution, the renal hemodynamic response resembled the reaction to a pyrogen (46) or to a concentrated albumin injection (23) in a normal or a hypertensive subject on a full diet; the renal plasma flow increased to normal or supranormal values, but the glomerular filtration rate was not affected appreciably. Thus, in the patients on a restricted salt intake the intrarenal mechanism for maintaining the glomerular filtration rate (47) may be set at a lower homeostatic level.

The stimulus activating the change in the set- ting of this intrarenal homeostat in subjects on the rice diet must await further elucidation. The prompt increase in filtration rate with concentrated sodium infusions or addition of salt to the diet of patients on restricted intakes tends to implicate some factor in sodium metabolism. Several investigators $(5,48,49)$ have suggested that there is some mechanism relating renal hemodynamics, particularly filtration, to extracellular fluid volume. But more evidence must be obtained before it can be accepted that changes in extracellular fluid volume, which is greatly affected by salt intake, can influence renal function in man.

The changes in glomerular filtration rate with variations in sodium chloride intake may be of particular significance in light of the recent analysis by Wesson, Anslow, and Smith (5) of the partition of electrolyte reabsorption between proximal and distal tubular segments of the mammalian kidney. They have advanced the hypothesis that there may be a maximal rate of distal tubular reabsorption of sodium or $T_{\text {mDNa }}$. When the load of filtered sodium delivered to the distal tubules exceeds this $T_{m D N a}$, the excess sodium appears quantitatively in the urine. Conversely, when the quantity of filtered sodium decreases and the amount delivered to the distal tubule falls below the $T_{\mathrm{mDNa}}$, sodium excretion diminishes markedly. Thus, the filtration rate, by virtue of its effect on the electrolyte load delivered to the distal tubules, may play a much more important role in controlling sodium excretion than hitherto has been suspected.

Because of the importance of the kidney in the conservation of extracellular electrolytes (50), it would seem a priori that not one but several renal mechanisms function in regulating the excretion of the principal extracellular cation, sodium. The role of adrenal cortical steroids in promoting tubular reabsorption of sodium in adaptation to heat (51), salt depletion (29), hemorrhage $(2,52)$, and possibly circulatory failure (52) is established. However, by applying Smith's hypothesis (5), much of the reported increased tubular reabsorption of sodium may be explained satisfactorily as a consequence of the decrease in glomerular filtration rate which may occur in each of these situations. This hypothesis also permits a hemodynamic explanation of the 
absence of proportionality between sodium clearance and filtration rate (53) and the virtual disappearance of sodium from the urine in severe congestive failure, when the glomerular filtration rate may be reduced only to $50 \%$ of normal.

Probably, both humoral $(51,54)$ and hemodynamic mechanisms for conserving sodium are activated whenever the organism responds to a stimulus strong enough to lead to sodium retention. The adaptive significance of this dual system for regulating salt excretion is apparent. The two controlling mechanisms permit both rapid and more chronic adjustment of electrolyte excretion to the needs of the organism. Moreover, under varying circumstances, this balance can be achieved with minimal change in renal tubular and endocrine activity, particularly under conditions of sustained increase or decrease in electrolyte intake. Finally, each system can compensate, in part, for failure of the other to respond appropriately or rapidly enough in a given situation.

The confirmation of Farnsworth's findings (55) that sodium and chloride excretion may parallel water output during water diuresis in hypertensives raises again the question of early renal involvement in hypertension. A possible criticism of Farnsworth's data has been that her patients had advanced hypertensive vascular disease with damaged renal tubules which, therefore, were leaking electrolytes. However, in the present series, hypertensives with fairly normal filtration rates and $\mathrm{T}_{\mathrm{mPAHs}}$ exhibited the same parallelism between water and salt excretion. Earle (56) has recently demonstrated that there may be no exact correlation between various tubular functions in renal disease; yet, it is significant that the electrolyte leakage by the hypertensive kidney may precede depression of glomerular filtration rate or even of $T_{\text {mPAB }}$, which has been considered the first sign of functional renal impairment in hypertension (9).

The present data suggest that there may be two possible dangers of a very low sodium diet for hypertensives. The first is the marked drop in glomerular filtration rate, which in patients with reduced renal function may lead to a severe or even fatal azotemia, particularly if sodium loss is accelerated by the administration of mercurial diuretics $(57,58)$; and the second is the rapid loss of extracellular electrolyte in hypertensives with more advanced renal disease. However, in most hypertensives, the loss of electrolyte and decrease in renal function are not sufficiently serious to outweigh the possible benefits of this dietary therapeutic experiment, when properly supervised.

\section{SUMMARY}

The effect of low salt cardiac and Kempner rice diets on renal hemodynamics, electrolyte excretion, and serum electrolytes was studied in a series of hypertensive patients who were on each regimen for relatively short periods.

On the low salt diet, no conclusive changes in renal plasma flow, renal arteriolar resistances, $\mathrm{T}_{\mathrm{mPAH}}$, plasma volume, and serum sodium and chloride occurred, but in five of six patients there was a decrease in glomerular filtration rate.

On the rice diet, with the added use of mercurial diuretics in several patients, more definitive changes occurred. In all nine hypertensive patients and in one non-hypertensive subject, there resulted a significant decrease in glomerular filtration rate, a smaller decrease in renal plasma flow, and a reduction in filtration fraction. In seven patients there was a decrease in renal afferent arteriolar resistance. In five patients there was a fall in plasma volume and in three of five a decrease in $T_{\text {mPAH. }}$. In those patients with initially reduced renal function, serum sodium and chloride fell.

In two patients on the rice diet, when plasma volume was rapidly increased by infusing isotonic, salt-poor serum albumin solutions, renal plasma flow returned to control values but the reduced glomerular filtration rate was not altered. In another patient, the reduced filtration rate and renal plasma flow on the rice diet were not affected by dibenamine. In contrast, infusions of hypertonic sodium solutions in one hypertensive and one non-hypertensive subject on the rice diet were associated with a significant increase of glomerular filtration rate and a rise in renal plasma flow above full diet control values.

On all three diets, 24-hour sodium and chloride outputs agreed well with known intake. However, in contrast to normal subjects, the hypertensives exhibited a proportionality between urine volume and electrolyte output during water and mannitol diuresis. This electrolyte leakage 
may be the earliest sign of renal tubular damage in hypertension.

The possible role of alterations in renal hemodynamics, and particularly decreased filtration, in conserving electrolyte during restricted salt intake is discussed from the point of view of glomerular-tubular balance. Adrenal cortical hormone regulation of tubular reabsorption of electrolyte is also considered.

\section{ACKNOWLEDGMENT}

The authors gratefully acknowledge the technical aid of the Misses Sybil Goldat and Margaret A. Rosenberg, Mrs. Madie Ross, and Mr. George Ross, chemists, Medical Division, and the assistance of Miss Honora E. Guerin, Dietician, and Miss Anne Goehring, Nurse, on the Metabolic Ward.

\section{BIBLIOGRAPHY}

1. Smith, H. W., The excretion of water. Bull. New York Acad. Med., 1947, 23, 177.

2. Borst, J. G. G., The maintenance of an adequate cardiac output by the regulation of urinary excretion of water and sodium chloride: An essential factor in the genesis of oedema. Acta med. Scandinav., 1948, 130, Suppl. 207.

3. Shannon, J. A., Jolliffe, N., and Smith, H. W., The excretion of urine in the dog. IV. The effect of maintenance diet, feeding, etc. upon the quantity of glomerular filtrate. Am. J. Physiol., 1932, 101, 625.

4. Van Slyke, D. D., Rhoads, C. P., Hiller, A., and Alving, A., The relationship of the urea clearance to the renal blood flow. Am. J. Physiol., 1934, 110, 387.

5. Wesson, L. G., Jr., Anslow, W. P., Jr., and Smith, H. W., The excretion of strong electrolytes. Bull. N. Y. Acad. Med., 1948, 24, 586.

6. Kempner, W., Compensation of renal metabolic dysfunction: Treatment of kidney disease and hypertensive vascular disease with rice diet. North Carolina M. J., 1945, 6, 61.

7. Fishberg, A. M., Hypertension and Nephritis. Lea and Febiger, Phila., 1939, 4th Ed.

8. Weston, R. E., and Escher, D. J. W., An analysis of the unresponsiveness to mercurial diuretics observed in certain patients with severe chronic congestive failure. J. Clin. Invest., 1948, 27, 561.

9. Goldring, W., and Chasis, H., Hypertension and $\mathrm{Hy}$ pertensive Disease. The Commonwealth Fund, New York, 1944.

10. Gibson, J. G., 2nd, and Evelyn, K. A., Clinical studies of blood volume. IV. Adaptation of the method to the photoelectric microcolorimeter. J. Clin. Invest., 1938, 17, 153.

11. Barker, H. G., and Clark, J. K., Effect of paraaminohippurate on mannitol determinations by the periodate-iodide-thiosulfate method. Proc. Soc. Exper. Biol. \& Med., 1947, 64, 120.

12. Butler, A. M., and Tuthill, E., An application of the uranyl zinc acetate method for the determination of sodium in biological material. J. Biol. Chem., 1931, 93, 171.

13. Harvey, S. C., The quantitative determination of the chlorides in the urine. Arch. Int. Med., 1910, 6, 12.

14. Van Slyke, D. D., and Hiller, A., Application of Sendroy's iodometric chloride titration to proteincontaining fluid. J. Biol. Chem., 1947, 167, 107.

15. Van Slyke, D. D., and Kugel, V. H., Improvements in manometric micro-Kjeldahl and blood urea methods. J. Biol. Chem., 1933, 102, 489.

16. Folin, O., On the determination of creatinine and creatine in urine. J. Biol. Chem., 1914, 17, 469.

17. Lauson, H. D., Personal communication.

18. Campbell, W. R., and Hanna, M. I., The albumin, globulins, and fibrinogen of serum and plasma. J. Biol. Chem., 1937, 119, 15.

19. Berger, E. Y., Farber, S. J., and Earle, D. P., Jr., Renal excretion of mannitol. Proc. Soc. Exper. Biol. \& Med., 1947, 66, 62.

20. Fisher, R. A., Statistical Methods for Research Workers. Oliver and Boyd, London, 1946, 10th Ed.

21. Barclay, J. A., Cooke, W. T., and Kenney, R. A., Observations on the effects of adrenalin on renal function and circulation in man. Am. J. Physiol., 1947, 151, 621.

22. Lyons, R. H., Jacobson, S. D., and Avery, N. L., Effect on the plasma volume of dehydration produced by a low salt diet and ammonium chloride. Am. Heart J., 1944, 27, 353.

23. Cargill, W. H., Effect of the intravenous administration of human serum albumin on renal function. Proc. Soc. Exper. Biol. \& Med., 1948, 68, 189.

24. Escher, D. J. W., Grossman, J., Leiter, L., Mokotoff, R., and Weston, R. E., Unpublished observations.

25. Lamport, $H$., Improvements in calculation of renal resistance to blood flow. Charts for osmotic pressure and viscosity of blood. J. Clin. Invest., 1943, 22, 461.

26. Cope, C. L., Studies of urea excretion. Effects on urea clearance of changes in protein and salt contents of the diet. J. Clin. Invest., 1933, 12, 567.

27. Goldring, W., Razinsky, L., Greenblatt, M. I., and Cohen, S., Influence of protein intake on urea clearance in normal man. J. Clin. Invest., 1934, 13, 743.

28. Longley, L. P., and Miller, M., Effect of diet and meals on maximum urea clearance. Am. J. Med. Sc., 1942, 203, 253.

29. McCance, R. A., and Widdowson, E. M., Secretion of urine in man during experimental salt deficiency. J. Physiol., 1937, 91, 222.

30. Hickey, R. C., and Hare, K., The renal excretion of chloride and water in diabetes insipidus. J. Clin. Invest., 1944, 23, 768. 
31. Mokotoff, R., Ross, G., and Leiter, L., Renal plasma flow and sodium reabsorption and excretion in congestive heart failure. J. Clin Invest., 1948, 27, 1.

32. Hare, R. S., Hare, K., and Phillips, D. M., Renal excretion of chloride by the normal and by the diabetes insipidus dog. Am. J. Physiol., 1944, 140, 334.

33. Chasis, H., Goldring, W., Breed, E., Bolomey, A., and Smith, H. W., Effects of salt and protein restriction on blood pressure and renal hemodynamics in hypertensive patients. J. Clin. Invest., 1949, 28, 775.

34. Currens, H., Reid, E. A. S., MacLachlan, E. A., Terry, M. L., Butler, A. M., and White, P. D., Physiologic, metabolic and electrolyte balance studies of hypertensive patients while on the rice diet. J. Clin. Invest., 1949, 28, 776.

35. Sirota, J., Personal communication.

36. Cargill, W. H., Personal communication.

37. Bradley, S. E., Personal communication.

38. Rhoads, C. P., Van Slyke, D. D., Hiller, A., and Alving, A. S., The effect of novocainization and total section of the nerves of the renal pedicle on renal blood flow and function. Am. J. Physiol., 1934, 110, 392.

39. Talbott, J. H., Castleman, B., Smithwick, R. H., Melville, R. S., and Pecora, L. J., Renal biopsy studies correlated with renal clearance observations in hypertensive patients treated by radical sympathectomy. J. Clin. Invest., 1943, 22, 387.

40. Smith, H. W., Rovenstine, E. A., Goldring W., Chasis H., and Ranges, H. A., The effects of spinal anesthesia on the circulation in normal, unoperated man with reference to the autonomy of the arterioles, and especially those of the renal circulation. J. Clin. Invest., 1939, 18, 319.

41. Mokotoff, R., and Ross, G., The effect of spinal anesthesia on the renal ischemia in congestive heart failure. J. Clin. Invest., 1948, 27, 335.

42. Turner, H., James, D. F., and Merrill, A. J., Studies on the mechanism of reduction in renal flow in congestive heart failure. Am. J. Med., 1948, 5, 619.

43. Corcoran, A. C., Kohlstaedt, K. G., and Page, I. H., Changes of arterial blood pressure and renal hemodynamics by injection of angiotonin in human beings. Proc. Soc. Exper. Biol. \& Med., 1941, 46, 244.

44. Edelman, I. S., Zweifach, B. W., Escher, D. J. W., Grossman, J., Mokotoff, R., Weston, R. E., Leiter, L., and Shorr, E., Studies on VEM and VDM in blood in relation to renal hemodynamics and renal oxygen extraction in chronic congestive heart failure. J. Clin. Invest., in press.

45. Chasis, H., Ranges, H. A., Goldring W., and Smith, H. W., The control of renal blood flow and glomerular filtration in normal man. J. Clin. Invest., 1938, 17, 683.

46. Bradley, S. E., Chasis, H., Goldring, W., and Smith, H. W., Hemodynamic alterations in normotensive and hypertensive subjects during the pyrogenic reaction. J. Clin. Invest., 1945, 24, 749.

47. Smith, H. W., Lectures on the Kidney. University Extension Division, University of Kansas, Lawrence, Kansas, 1943.

48. Shannon, J. A., Control of the renal excretion of water. I. The effect of variations in the state of hydration on water excretion in dogs with diabetes insipidus. J. Exper. Med., 1942, 76, 371.

49. Newman, E. V., Bordley, J., and Winternitz, J., The interrelationships of glomerular filtration rate (mannitol clearance), extracellular fluid volume, surface area of the body and plasma concentration of mannitol. Bull. Johns Hopkins Hosp., 1944, 75, 253.

50. Gamble, J. L., Chemical Anatomy, Physiology and Pathology of Extracellular Fluid. Harvard University Press, Cambridge, Mass., 1947.

51. Conn, J. W., Electrolyte composition of sweat : clinical implications of adrenal cortical function. Arch. Int. Med., 1949, 83, 416.

52. Dock, W., Heart failure: the relation of symptoms and signs to its severity and duration. Ann. Int. Med., 1948, 29, 11.

53. Sinclair-Smith, B., Kattus, A. A., Genest, J., and Newman, E. V., The renal mechanism of electrolyte excretion and the metabolic balances of electrolytes and nitrogen in congestive cardiac failure: the effects of exercise, rest and aminophyllin. Bull. Johns Hopkins Hosp., 1949, 84, 369.

54. Leaf, A., and Couter, W. T., Evidence that renal sodium excretion by normal human subjects is controlled by adrenal cortical activity. J. Clin. Invest., 1949, 28, 1067.

55. Farnsworth, E. B., Renal reabsorption of chloride and phosphate in normal subjects and patients with essential arterial hypertension. J. Clin. Invest., 1946, 25, 897.

56. Earle, D. P., Jr., Personal communication.

57. Schroeder, H. A., Low salt diets and arterial hypertension. Am. J. Med., 1948, 4, 578.

58. MacGuire, W. B., Risk of uremia due to sodium depletion. J.A.M.A., 1948, 137, 1377. 